\title{
Accumulative occlusion time correlates with postoperative pulmonary complications in patients undergoing pelvic and sacrum tumor resection assisted by abdominal aortic balloon occlusion: a retrospective cohort study
}

\author{
Junjun $\mathrm{Xu}^{1+}$, Huiying Zhao ${ }^{2+}$, Xiaodan Zhang ${ }^{1}$ and Yi Feng ${ }^{1 *}$ (D)
}

\begin{abstract}
Background: Postoperative pulmonary complications (PPCs) seems to be high in patients undergoing pelvic and sacrum tumor resection assisted by abdominal aortic balloon occlusion. We hypothesized that the accumulative occlusion time (AOT) of the abdominal aortic balloon may be predictive of PPCs. The objective of the study was to identify the influence of AOT on PPCs.

Methods: Retrospectively analyzed perioperative factors of 584 patients who underwent pelvic and sacrum tumor resection assisted by abdominal aortic balloon occlusion in our hospital from January 1, 2016 to December 31, 2018. PPCs including suspected pulmonary infection, atelectasis, pulmonary edema, pleural effusion, respiratory failure were clinically diagnosed. Perioperative parameters among patients with and without PPCs were compared. A receiver operating characteristic (ROC) analysis was conducted to evaluate the discriminative power of AOT with regard to PPCs. A multivariate logistic-regression model was finally established to identify independent risk factors for PPCs.

Results: The incidence of PPCs was 15.6\% (91 patients). The median AOT in PPCs group was significantly higher than that in non-PPCs group $(P<0.001)$. The hospital stay was significantly prolonged in PPCs group $(P<0.001)$. The ROC analysis showed an AOT of 119 min as the threshold value at which the joint sensitivity $(88.60 \%)$ and specificity (31.87\%) was maximal. Finally, AOT $\geq 119 \mathrm{~min}(P=0.046$; odds ratio $(\mathrm{OR})=2.074)$, age $(P<0.001 ; \mathrm{OR}=$ 1.032), ASA grade III $(P=0.015 ; \mathrm{OR}=3.264)$, and estimated blood loss $(P=0.022 ; \mathrm{OR}=1.235)$ were independent risk factors of PPCs by multivariate logistic regression analysis.

(Continued on next page)
\end{abstract}

\footnotetext{
* Correspondence: doctor_yifeng@sina.com

†Junjun Xu and Huiying Zhao contributed equally to this work.

'Department of Anesthesiology, Peking University People's Hospital, No. 11

Xizhimen South Street, Xicheng District, Beijing 10044, China

Full list of author information is available at the end of the article
}

(c) The Author(s). 2020 Open Access This article is licensed under a Creative Commons Attribution 4.0 International License, which permits use, sharing, adaptation, distribution and reproduction in any medium or format, as long as you give appropriate credit to the original author(s) and the source, provide a link to the Creative Commons licence, and indicate if changes were made. The images or other third party material in this article are included in the article's Creative Commons licence, unless indicated otherwise in a credit line to the material. If material is not included in the article's Creative Commons licence and your intended use is not permitted by statutory regulation or exceeds the permitted use, you will need to obtain permission directly from the copyright holder. To view a copy of this licence, visit http://creativecommons.org/licenses/by/4.0/ The Creative Commons Public Domain Dedication waiver (http://creativecommons.org/publicdomain/zero/1.0/) applies to the data made available in this article, unless otherwise stated in a credit line to the data. 
(Continued from previous page)

Conclusion: The incidence of PPCs in patients undergoing the pelvic and sacrum tumor surgery assisted by abdominal aortic balloon occlusion was $15.6 \%$. AOT $\geq 119$ min was an independent predictor for PPCs. Surgeons should strive to minimize the AOT within $2 \mathrm{~h}$.

Keywords: Abdominal aortic balloon, Pelvic and sacrum tumor resection, Postoperative pulmonary complications, Ischemia-reperfusion lung injury

\section{Background}

Pelvic and sacrum tumors have an insidious onset and are difficult to diagnose at an early stage; in fact, when the tumor is eventually diagnosed, it has grown large and usually invades adjacent blood vessels, nerves and the rectum. The surgical excision of pelvic and sacrum tumors is very challenging, and is often associated with massive bleeding and a longer duration of surgery. Aortic occlusion is a surgical technique to minimize ongoing hemorrhage by decreasing distal arterial blood flow and pressure to injured organs or vessels [1], which is classically achieved by cross-clamping the aorta. In the past few decades, there has been increasing use of endovascular balloon occlusion of the aorta in the management of traumatic hemorrhage [2] and other clinical settings, such as surgeries of pelvic and sacrum tumors [3-5], prophylactic use in women with abnormal placentation [6] and patients with non-traumatic out-of-hospital cardiac arrest [7]. The application of abdominal aortic balloon occlusion in the excision of pelvic and sacrum tumors can effectively control intraoperative bleeding, shorten the duration of surgery, reduce the surgical complications, and improve the effectiveness and safety of the surgery $[3,4]$.

Compared with other malignant tumors, primary malignant bone tumors usually develop in young adults which have better preoperative basal pulmonary function. However, in the clinical setting, we found that the incidence of postoperative pulmonary complications (PPCs) is high, which may be associated with the longer operation and mechanical ventilation time, as well as greater intraoperative blood loss and blood transfusion. Moreover, the ischemia-reperfusion lung injury following the deflation of the abdominal aortic balloon may also contribute to the PPCs. As the extent of tissue injury usually relates to the extent of reduction in blood flow and to the length of the ischemic period, which influence the cellular level of ATP production and the reduction of intracellular $\mathrm{pH}$ [8], we hypothesized that the accumulative occlusion time (AOT) of the abdominal aorta occlusion may be a predictive factor of PPCs in patients undergoing pelvic and sacrum tumor resection assisted by abdominal aorta occlusion.
Previous studies on lung injury after aortic balloon application have mainly been conducted in animals $[9,10]$, or have included a small sample size [11]. Due to the low incidence of pelvic and sacrum tumors, to our knowledge, no study has assessed the incidence of and factors associated with PPCs in patients undergoing pelvic and sacrum tumor resection with abdominal aortic balloon occlusion. In the present study, we aimed to retrospectively analyze the factors associated with PPCs in these patients, especially the influence of AOT on the PPCs, so as to recommend optimal perioperative management measures and improve patient prognosis.

\section{Methods}

\section{Study design overview}

It was a retrospective cohort study approved by our local institutional review board (IRB no.2019PHB038-01; approved on February 28, 2019). We reviewed the medical records of 584 consecutive patients who underwent pelvic and sacrum tumor resection assisted by abdominal aortic balloon occlusion in Peking University People's Hospital from January 1, 2016 to December 31, 2018.

\section{Surgical technique}

After induction of general anesthesia, a balloon dilation catheter (MAXI LD; Cordis, a Johnson and Johnson company, Bridgewater, New Jersey) was inserted into the lower abdominal aorta through an $11 \mathrm{~F}$ percutaneous introducer sheath (CROSSOVER; Cordis) inserted into the femoral artery about $1 \mathrm{~h}$ before surgery. An appropriate location of the balloon was confirmed distal to the renal arteries and proximal to abdominal aortic bifurcation under fluoroscopy. When the tumor was fully exposed, the abdominal aortic balloon was inflated at an appropriate time according to the experience of the surgeon to facilitate the surgical operation and reduce bleeding. The occlusion time of the balloon was determined by the surgeon during the surgical procedure. To avoid a sudden decrease of circulating blood volume, the balloon was deflated gradually. The occlusion of the balloon may be applied more than once as necessary during the surgery. Massive infusion and vasopressors were often needed. The balloon catheter was removed after 
surgery. The accumulative occlusion time (AOT) of the abdominal aorta was recorded.

\section{Anesthesia and postoperative pain management}

All patients were placed under general anesthesia. After induction with intravenous propofol, sufentanil and cisatracurium, endotracheal intubation and mechanical ventilation were performed. Maintenance anesthesia consisted of continuous infusion of propofol, remifentanil and cisatracurium. Cis-atracurium was stopped infusing at least $1 \mathrm{~h}$ before the end of surgery. All patients received routine monitoring of invasive arterial pressure, electrocardiogram, pulse oxygen saturation, end-tidal carbon dioxide, central venous pressure, bispectral index (BIS), nasal temperature, urine output and arterial blood gas. Two large bore peripheral intravenous catheters were placed. The fluid of choice for these procedures was lactated Ringer's solution as crystalloid and 6\% hydroxyethylstarch 130/0.4 as colloid. Blood transfusions, including transfusion of packed red blood cells (PRBCs) and plasma, were performed based on the amount of intraoperative bleeding, the level of hematocrit, and the anesthesiologists' judgments. Postoperative analgesia was delivered through a patient-controlled analgesia pump.

\section{Diagnosis of postoperative pulmonary complications}

In accordance with the previous studies [12, 13], postoperative pulmonary complications included suspected pulmonary infection, atelectasis, pulmonary edema, pleural effusion and respiratory failure. In this study, these diagnoses were identified in medical records, radiographic reports, and/or the discharge summary. The definitions of PPCs $[12,13]$ were listed in Table 1.

\section{Preoperative and intraoperative parameters and postoperative outcomes}

Patients who had developed PPCs during their hospital stay were compared with their non-PPCs counterparts. Preoperative parameters included age, gender, ASA grade, body mass index (BMI), smoking status (current smoker), pulmonary co-morbidities (including lung cancer, lung metastases, chronic obstructive pulmonary disease, asthma, etc.), preoperative hemoglobin value and preoperative albumin value. The intraoperative parameters included duration of surgery, intraoperative estimated blood loss, AOT of abdominal aortic balloon.

The main outcome was the incidence of PPCs occurring during the hospital stay. According to the severity of PPCs, patients were classified as mild $\left(\mathrm{PaO}_{2} \geq 60\right.$ $\mathrm{mmHg}, 8 \mathrm{kPa}$, or $\mathrm{SpO}_{2} \geq 90 \%$ in room air and only needing mask or nasal supplementary oxygen), moderate $\left(\mathrm{PaO}_{2}<60 \mathrm{mmHg}, 8 \mathrm{kPa}\right.$, or $\mathrm{SpO}_{2}<90 \%$ in room air but responding to mask or nasal supplementary oxygen, excluding hypoventilation) and severe $\left(\mathrm{PaO}_{2}<60 \mathrm{mmHg}\right.$, $8 \mathrm{kPa}$, or $\mathrm{SpO}_{2}<90 \%$ and needing invasive or noninvasive mechanical ventilation support) [12]. The secondary outcome was the length of hospital stay.

\section{Statistical data analyses}

Stata software, version 15.1 (Stata Corp) was used to accomplish the following statistical analyses. Continuous data were expressed as means with standard deviations or as medians with interquartile ranges, depending on normality. Categorical variables were shown as proportions. In the univariate testing, patients who had developed PPCs were compared with their non-PPCs counterparts. For the comparison between the 2 groups,

Table 1 Definitions of postoperative pulmonary complications

\begin{tabular}{|c|c|}
\hline Complications & Definitions \\
\hline $\begin{array}{l}\text { Suspected pulmonary } \\
\text { infection }\end{array}$ & $\begin{array}{l}\text { General signs of infection, at least one of the following criteria: patient received antibiotics, core body temperature }> \\
38^{\circ} \mathrm{C} \text {, leukocytosis }>12,000 \text { cells per } \mu \mathrm{L} \text {; and signs of an infection of pulmonary origin, at least one of the following } \\
\text { criteria: new or changed sputum, or new or changed lung opacity on chest X-ray when clinically indicated. }\end{array}$ \\
\hline Atelectasis & $\begin{array}{l}\text { Lung opacification with shift of the mediastinum, hilum, or hemidiaphragm towards the affected area and compensatory } \\
\text { overinflation of the adjacent non-atelectatic lung. }\end{array}$ \\
\hline Pulmonary edema & $\begin{array}{l}\text { Defined as diffuse alveolar interstitial infiltrates with dyspnea and rales related to left ventricular failure, confirmed by one } \\
\text { of the following: echocardiography, pulmonary catheter, or clinical improvement with specific treatment. }\end{array}$ \\
\hline Pleural effusion & $\begin{array}{l}\text { Chest X-ray demonstrating blunting of the costophrenic angle, loss of the sharp silhouette of the ipsilateral hemidiaph- } \\
\text { ragm in upright position, evidence of displacement of adjacent anatomical structures, or (in supine position) a hazy opa- } \\
\text { city in one hemithorax with preserved vascular shadows. }\end{array}$ \\
\hline \multicolumn{2}{|l|}{ Respiratory failure } \\
\hline Mild & $\begin{array}{l}\mathrm{PaO}_{2}<60 \mathrm{mmHg}, 8 \mathrm{kPa} \text {, or } \mathrm{SpO}_{2}<90 \% \text { in room air but responding to mask or nasal supplementary oxygen (excluding } \\
\text { hypoventilation). }\end{array}$ \\
\hline Intermediate & $\begin{array}{l}\mathrm{PaO}_{2}<60 \mathrm{mmHg}, 8 \mathrm{kPa} \text {, or } \mathrm{SpO}_{2}<90 \% \text { and needing invasive or non-invasive mechanical ventilation (excluding } \\
\text { hypoventilation) }\end{array}$ \\
\hline Severe & $\begin{array}{l}\mathrm{PaO}_{2} \text {-to- } \mathrm{FiO}_{2} \text { ratio }<300 \mathrm{mmHg} \text { or } 40 \mathrm{kPa} \text { regardless of level of PEEP, needing invasive mechanical ventilation (acute lung } \\
\text { injury or acute respiratory distress syndrome). }\end{array}$ \\
\hline
\end{tabular}

Abbreviation: $\mathrm{PaO}_{2}$ partial pressure of oxygen in arterial blood, $\mathrm{SpO}_{2}$ peripheral blood oxygen saturation, FiO $_{2}$ fractional concentration of oxygen in inspired air PEEP positive end-expiratory pressure 
categorical variables were analyzed using Pearson chisquare tests or Fisher exact tests as appropriate. Continuous variables were performed using Kruskal-Wallis equality-of-populations rank tests. The receiver operating characteristic (ROC) analysis was conducted to evaluate the discriminative power of AOT with regard to PPCs. The area under curve (AUC) with its 95\% confidence interval (CI) was then extrapolated. The best cutoff value of the AOT was identified according to the sensitivity and specificity. Predictors with a $P$ value of $<$ 0.1 on univariate analysis were identified to be risk factors of PPCs. The variance inflation factor (VIF) and tolerance were used to test the multicollinearity of the risk factors. A VIF $>10$ or tolerance $<0.1$ was identified to be significant multicollinearity. Binary multivariate logistic regression was used to determine independent risk factors of PPCs. The Hosmer-Lemeshow test was used to estimate the goodness of fit for the logistic regression mode. A coefplot was performed to plot the regression coefficients. We used a nomogram to demonstrate the risk points and probability of independent risk factors for PPCs. A $P$ value of $<0.05$ in 2 -sided tests was statistically significant.

\section{Results}

\section{Study population}

Of 591 patients initially identified as potential candidates, 7 patients were excluded from the final analysis because the abdominal aortic balloon was placed in the abdominal aorta but not used during the surgery $(n=4)$; or the occlusion time of the abdominal aortic balloon was not recorded $(n=3)$. Therefore, a total of 584 patients were included in the study. The preoperative variables and the intraoperative variables were summarized (Table 2).

\section{Summary of postoperative pulmonary complications and the length of hospital stay}

Of the 584 patients, 91 (15.6\%) exhibited pulmonary complications, including suspected pulmonary infection in $64(11.0 \%$, with 60 patients diagnosed with Chest Xray, 4 patients diagnosed based on clinical symptoms and signs, including fever, leukocytosis and new sputum), pleural effusion in $36(6.2 \%$, with all the patients diagnosed with Chest X-ray), atelectasis in 17 (2.9\%, with 12 patients diagnosed with CT scans, 5 patients diagnosed with Chest X-ray as recorded in the radiographic reports), pulmonary edema in $6(1.0 \%$, with 5 patients diagnosed with Chest X-ray, 1 patient diagnosed with Chest X-ray and CT scans) and respiratory failure in 4 (0.7\%, with all the patients diagnosed with arterial blood gas analysis).

Of the 91 patients with PPCs, according to the severity of PPCs, 87 patients were classified as mild (95.6\%), 2 patients were classified as moderate (2.2\%), and 2 patients were classified as severe $(2.2 \%)$. No death was noted in any of the cases.

Compared with non-PPCs group, the length of hospital stay was significantly longer in PPCs group $(P<0.001)$ (Table 2).

Table 2 Perioperative variables of patients with or without PPCs

\begin{tabular}{|c|c|c|c|c|}
\hline Variables & Overall $(n=584)$ & With PPCs $(n=91)$ & Without PPCs $(n=493)$ & $P$ value \\
\hline Age (y) & $45.5(31-55)$ & $51(36-62)$ & $44(30-54)$ & $<0.001$ \\
\hline Gender, male (\%) & $307(52.6 \%)$ & $43(47.3 \%)$ & $264(53.6 \%)$ & 0.269 \\
\hline BMI & $23.0(20.3-25.3)$ & $23.0(20.0-25.7)$ & $22.9(20.4-25.1)$ & 0.775 \\
\hline ASA grade & & & & 0.001 \\
\hline Grade I (\%) & $158(27.1 \%)$ & $15(16.5 \%)$ & $143(29.0 \%)$ & \\
\hline Grade II (\%) & $388(66.4 \%)$ & $63(69.2 \%)$ & $325(65.9 \%)$ & \\
\hline Grade III (\%) & $38(6.5 \%)$ & $13(14.3 \%)$ & $25(5.1 \%)$ & \\
\hline Pulmonary co-morbidities (\%) & $63(10.8 \%)$ & $12(13.2 \%)$ & $51(10.3 \%)$ & 0.422 \\
\hline Current smoker (\%) & $64(11.0 \%)$ & $14(15.4 \%)$ & $50(10.1 \%)$ & 0.141 \\
\hline Preoperative Albumin (g/L) & $41.3(38.8-44)$ & $40.7(37.1-43.3)$ & $41.4(39.0-44.1)$ & 0.066 \\
\hline Preoperative Hemoglobin ( $g / L)$ & $130(118-142)$ & $128(113-142)$ & $130(119-142)$ & 0.307 \\
\hline Estimated blood loss (L) & $1.5(0.8-2.5)$ & $2.15(1.0-3.9)$ & $1.5(0.8-2.2)$ & $<0.001$ \\
\hline Duration of surgery (h) & $4.1(3.2-5.6)$ & $5.2(3.5-7.1)$ & $4.0(3.1-5.3)$ & $<0.001$ \\
\hline Accumulative occlusion time (min) occlusion time (min) & $80(58-104.5)$ & $91(66-129)$ & $77(57-102)$ & $<0.001$ \\
\hline$\geq 119 \min (\%)$ & $85(14.6 \%)$ & $29(31.9 \%)$ & $56(11.4 \%)$ & $<0.001$ \\
\hline Length of stay (d) & $22(18-28)$ & $27(20-36)$ & $22(18-27)$ & $<0.001$ \\
\hline
\end{tabular}

The data are presented as the median (25-75\% interquartile range) or number (percentage)

Abbreviation: PPCs postoperative pulmonary complications, BMI body mass index, ASA American Society of Anesthesiologists 
ROC analysis on the prediction of accumulative occlusion time for PPCs

The ROC analysis of AOT showed an AUC 0.62 (95\% $\mathrm{CI}=0.55-0.68$ ) for the prediction of PPCs (see Fig. 1). According to the ROC curve, an AOT of 119 min was found to be the optimal cutoff value with the maximum joint sensitivity $(88.60 \%)$ and specificity $(31.87 \%)$. Therefore, $\mathrm{AOT} \geq 119 \mathrm{~min}$ was determined as the threshold value for predicting the risk of PPCs. On the basis of the threshold value of AOT, there were 499 patients with $\mathrm{AOT}<119 \mathrm{~min}$ and 85 patients with $\mathrm{AOT} \geq 119 \mathrm{~min}$, respectively, which were also summarized in Table 2 .

\section{Univariate analysis}

The AOT of abdominal aortic balloon $(P<0.001)$ was significantly longer in PPCs group, and the proportion of AOT equal or longer than $119 \mathrm{~min}(P<0.001)$ was also higher in PPCs group when compared with non-PPCs group. Patients with PPCs were older $(P<0.001)$, had a higher proportion of ASA grade III and a lower proportion of ASA grade I. The preoperative albumin value showed a trend toward a higher risk of PPCs $(P=0.066)$. Patients with PPCs had a significantly higher intraoperative estimated blood loss volume $(P<0.001)$ and a longer duration of surgery $(P<0.001)$ when compared with nonPPCs patients. No significant difference in gender, BMI, current smoker, pulmonary co-morbidities, and preoperative hemoglobin value was observed.

\section{Multivariate analysis}

We tested the multicollinearity of all the variables with a $P$ value of $<0.1$ on univariate analysis as mentioned above (Table 3 ). The results showed that the largest VIF of the above variables was 1.93 and the smallest tolerance was 0.518 . Therefore, we included all of them in the binary multivariate logistic regression model, and we found that $\mathrm{AOT} \geq 119 \mathrm{~min}$, age, ASA grade III, and

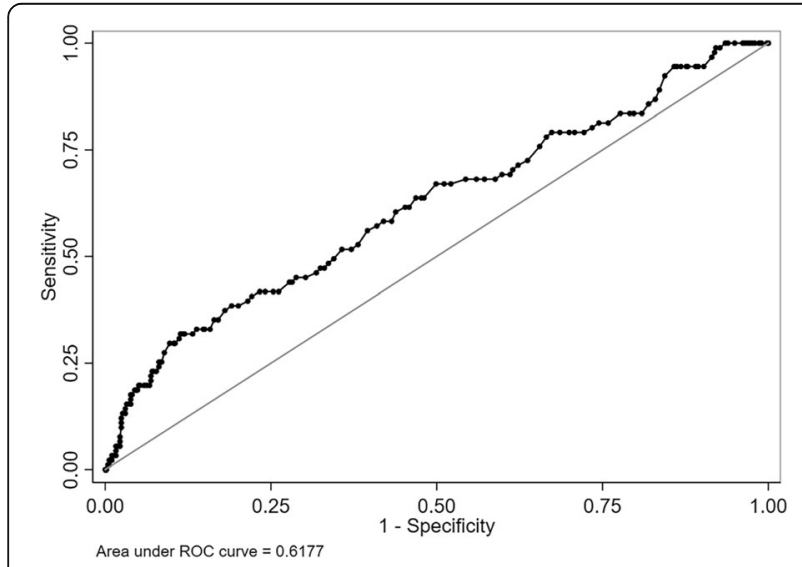

Fig. 1 The ROC curve of accumulative occlusion time for the prediction of postoperative pulmonary complications
Table 3 Multicollinearity test of risk factors of PPCS

\begin{tabular}{lll}
\hline Risk factors & VIF & Tolerance \\
\hline Age $(\mathrm{y})$ & 1.16 & 0.859 \\
ASA grade & 1.16 & 0.861 \\
Preoperative albumin (g/L) & 1.06 & 0.946 \\
Duration of surgery (h) & 1.93 & 0.518 \\
Estimated blood loss (L) & 1.85 & 0.542 \\
Accumulative occlusion time (min) & 1.57 & 0.637
\end{tabular}

Abbreviation: PPCs postoperative pulmonary complications, ASA American Society of Anesthesiologists, VIF variance inflation factor

estimated blood loss were independent risk factors of PPCs in patients undergoing excision of pelvic and sacrum tumors assisted by abdominal aortic balloon (Table 4). The Hosmer-Lemeshow test showed the fit for the multivariate logistic regression model was good $(P=0.165$, chi $2=602.9)$. The coefplot of the regression coefficients was shown in Fig. 2. These results revealed that $\mathrm{AOT} \geq 119 \mathrm{~min}$ was an independent risk factor of PPCs after adjusting the influence of age, ASA grade, preoperative albumin value, estimated blood loss volume, and duration of surgery.

\section{Nomogram}

Through the multivariate logistic regression model, we built a prognostic nomogram incorporating the above independent prognostic factors for visualization and facilitating clinical practice as shown in Fig. 3.

\section{Discussion}

To our knowledge, this is the first study to assess the risk factors associated with PPCs in patients undergoing pelvic and sacrum tumor resection assisted by abdominal aortic balloon occlusion, especially the influence of AOT on the incidence of PPCs in these patients. A retrospective analysis of 584 patients showed that the incidence of PPCs was $15.6 \%$, with suspected pulmonary infection, pleural effusion and atelectasis as the most common complications. The ROC analysis showed an AOT of $119 \mathrm{~min}$ as the optimal cutoff value with regard to risk of PPCs. Finally, an AOT $\geq 119$ min was identified to be an independent risk factor of PPCs after adjusting the influence of age, ASA grade, preoperative albumin value, estimated blood loss, and duration of surgery.

PPCs after major surgery are an important cause of death and morbidity [13, 14], and the duration of hospital stay was found to be significantly longer in patients at high risk of PPCs than in low-risk patients [15]. Therefore, the early identification of patients at high risk of PPCs can help us initiate preventive measures and provide appropriate treatment, which has important clinical significance. Recently, a multicenter prospective observational study named POPULAR showed that the 
Table 4 Multivariate logistic regression analysis of PPCs and clinical variables

\begin{tabular}{llll}
\hline Variables & OR & $P$ value & $95 \% \mathrm{Cl}$ \\
\hline Accumulative occlusion time $\geq 119 \min (\%)$ & 2.074 & 0.046 & $1.013-4.244$ \\
Age (y) & 1.032 & $<0.001$ & $1.014-1.050$ \\
ASA Grade III (\%) & 3.264 & 0.015 & $1.255-8.487$ \\
Estimated blood loss (L) & 1.235 & 0.022 & $1.031-1.479$ \\
\hline
\end{tabular}

Abbreviation: PPCs postoperative pulmonary complications, ASA American Society of Anesthesiologists

incidence of PPCs in patients who underwent noncardiac surgery with general anesthesia and muscle relaxants was $7.6 \%$, and that the high-risk types of surgery included intrathoracic surgery and upper abdominal laparotomy [12]. In our study, the incidence of PPCs in patients undergoing pelvic and sacrum tumor resection assisted by abdominal aortic balloon occlusion is $15.6 \%$, which is higher than the overall incidence of PPCs in the POPULAR study. Although most of the patients with PPCs were classified as mild, patients with PPCs have longer hospital stays compared with non-PPCs patients, which is consistent with previous result [15]. As predictive factors for PPCs, age [12, 13, 15], ASA physical status $[12,13,15]$ and estimated blood loss [16] have already been discussed thoroughly. For the first time, we found that patients with longer AOT had a higher probability of PPCs in these patients.

Pelvic and sacrum tumors are rich in blood supply, and hence, surgeries are often accompanied by extensive bleeding that can be difficult to control during tumor resection. In severe cases, extensive hemorrhage may lead to hemorrhagic shock or even death. The application of abdominal aortic balloon occlusion enables surgeons to obtain a good surgical field and surgical conditions, control the amount of bleeding, shorten the duration of surgery, and improve the thoroughness and safety of pelvic and sacrum tumor surgery $[3,4]$. However, accompanied by the inflation and deflation of the abdominal aortic balloon, the blood supply of the distal tissue is

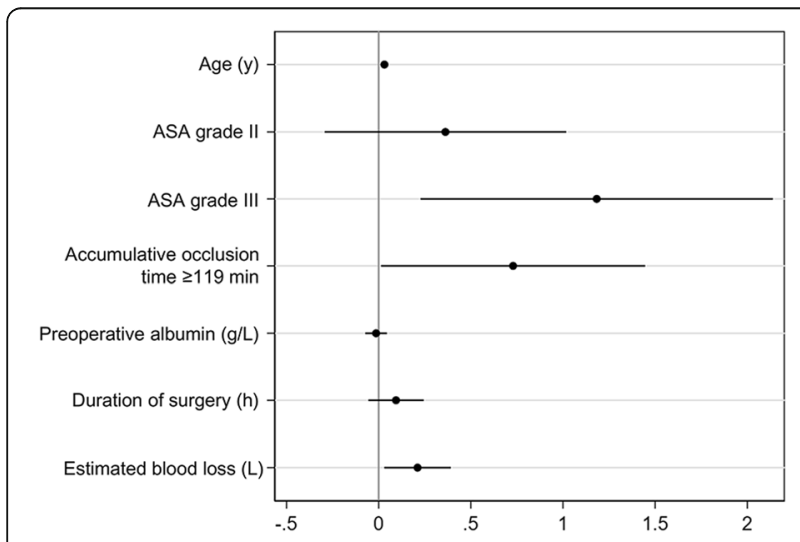

Fig. 2 Coefplot of the Logistic regression coefficient interrupted and recovered, and then ischemiareperfusion ( $I / R)$ injury occurs. In addition to the damage that occurs in the tissue which was subjected to the ischemia and reperfusion process, distal organs are also affected by this process, which may result in multiple organ dysfunction $[17,18]$, including lung injury [11, 19]. An animal study has assessed the occurrence of ischemia-reperfusion injury in cases undergoing abdominal aortic balloon occlusion for $30 \mathrm{~min}, 60 \mathrm{~min}$ and 120 min [9], and showed that the peak inspiratory pressure was significantly greater in samples with balloon occlusion of 120 min compared with baseline. Moreover, lung tissue biopsy of the 3 groups all showed alveolar congestion and atelectasis. So, ischemia-reperfusion lung injury induced by applying abdominal aortic balloon occlusion could contribute to the lung injury in these patients and the extent of the lung injury may be occlusion timedependent. This may be part of the reason why the incidence of PPCs in our study is so high. Clinicians should note that abdominal aorta balloon is a good tool for reducing bleeding, but the risk of lung injury should not be ignored.

The appropriate time to block the abdominal aortic balloon remains unclear. Current studies generally recommend limiting the single continuous balloon blockade time to $60-90 \mathrm{~min}$ to avoid damage to the arterial wall, ischemic necrosis of the distal limb, organ damage or multiple organ dysfunctions, and the balloon can be inflated again after 10-15 min if needed [20-22]. To our knowledge, no study has assessed the effect of the AOT when the aortic balloon was occluded more than once. In our study, we found that the AOT $\geq 119$ min was an independent risk factor for PPCs, and patients with AOT $\geq 119$ min were 2.07 times more likely to develop such complications compared to those with AOT less than 119 min. This result is of important clinical significance. It means that surgeons shouldn't only consider the occlusion time of a single time, but also the AOT when the occlusion was conducted more than once. Minimizing the AOT less than $2 \mathrm{~h}$ could be set as a first goal. However, the weight of AOT $\geq 119 \mathrm{~min}$ on the prediction of PPCs is not very great in the nomogram of this study.

The development of ischemia-reperfusion injury associated with sustained aorta balloon occlusion has 


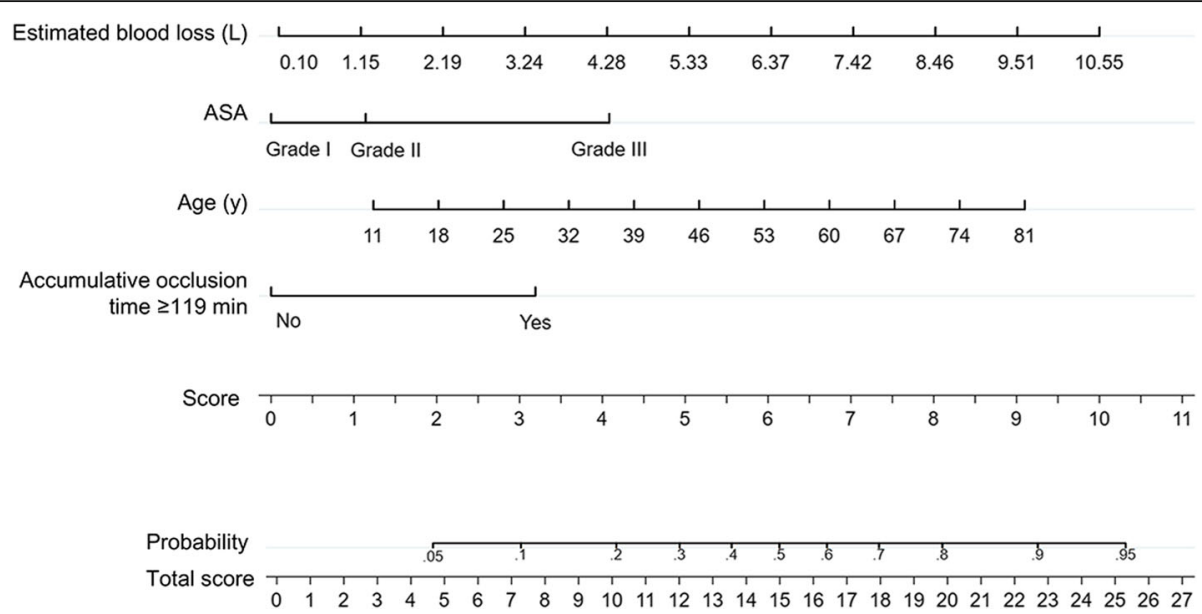

Fig. 3 Nomogram for postoperative pulmonary complications using the independent risk factors

prompted surgeons to seek measures to improve the blood supply of the distal tissues while maintain the effectiveness of controlling hemorrhage. In recent years, interests in intermittent [23] and partial blockade [24] are increasing, which involves the intermittent inflation to ensure tissue perfusion or partial inflation of the balloon to allow a certain degree of blood flow; however, none of these methods have been verified in large clinical trials. A new technique called endovascular variable aortic control (EVAC) has emerged as an promising alternative to partial resuscitative endovascular balloon occlusion of the aorta (REBOA), in which automated control of aortic occlusion is used to precisely and dynamically regulate distal aortic flow across the full spectrum from complete occlusion to full unimpeded flow [25]. Compared with standard REBOA, EVAC can improve hemodynamics, decrease metabolic derangements and resuscitation requirements over a $45 \mathrm{~min}$ intervention duration [26], but it still needs verification whether it is suitable for pelvic and sacrum tumor resections.

As to reduce the lung injury following ischemiareperfusion caused by abdominal aorta balloon occlusion, recent studies have given three clues. First, previous studies have showed that reactive oxygen species (ROS) and the inflammatory cytokines play an important role in the pathogenesis of ischemia-reperfusion induced lung injury $[27,28]$, and several protective agents have been introduced to target these. In a hind limb $I / R$ model in rats, edaravone exert a potent protective effect against lung injury induced through its antioxidant and anti-inflammatory activities [29]. Another animal study has also shown that Lazaroid U-74389G (an anti-lipid peroxidation drug) can reduce lung ischemia-reperfusion injury once the thoracoabdominal aortic occlusion has been relieved [10], and remains an avenue of future research. Second, in a rat model, the remote postconditioning was able to minimize the inflammatory lesion of the lung parenchyma of rats undergoing ischemia and reperfusion process caused by clamping the abdominal aorta [30], which seems more practical in clinical setting than remote-preconditioning. Third, a study showed that early ventilatory intervention will block progression to acute respiratory distress syndrome (ARDS) induced by ischemia-reperfusion and peritoneal sepsis. Airway pressure release ventilation (APRV) maintains a sustained airway pressure over a large proportion of the respiratory cycle, and therefore this ventilation strategy has a high pressure-time profile which can prevent alveolar edema and maintain alveolar stability throughout the ventilatory cycle [31]. In conclusion, comprehensive measures are needed to prevent the lung injury following ischemia-reperfusion caused by abdominal aorta balloon occlusion.

The present study has certain limitations. First, due to the limitations of retrospective studies, the collection of clinical data remains imperfect. For example, "smoking status" in patient data refers to current smokers who have not quit smoking, and no distinction was made between patients who had never smoked and those who had quit smoking. Second, the diagnosis of PPCs depends on the clinician's judgment, and was then confirmed via imaging and laboratory examinations. Therefore, some diseases without apparent symptoms might be ignored, such as mild pleural effusion, and atelectasis, which may lead to the underestimation of the incidence of postoperative pulmonary complications. Finally, the sample size of this study was relatively small, which limits the applicability of the results. In the future, a prospective study with a large sample size can be conducted, with the comprehensive collection of clinical data. In such studies, the factors associated with PPCs 
and their impact on short-term mortality and long-term survival rate can be assessed, and a series of measures can be initiated to reduce ischemia-reperfusion lung injury and provide suitable interventions. In addition, the present study could only observe a certain relationship between longer occlusion time and pulmonary complications, but their causal relationship was not clear, which may be further verified in the future research.

\section{Conclusions}

In conclusion, the incidence of PPCs in patients undergoing the pelvic and sacrum tumor surgery assisted by abdominal aortic balloon occlusion was $15.6 \%$. AOT $\geq$ 119 min was an independent risk factor for PPCs after adjusting the influence of age, ASA grade, preoperative albumin value, estimated blood loss, and duration of surgery. Clinicians should note that abdominal aorta balloon is a good tool for reducing bleeding, but the risk of lung injury should not be ignored. Surgeons should strive to minimize the AOT within $2 \mathrm{~h}$.

\begin{abstract}
Abbreviations
AOT: Accumulative occlusion time; APRV: Airway pressure release ventilation; ARDS: Acute respiratory distress syndrome; AUC: Area under curve; BIS: Bispectral index; BMI: Body mass index; Cl: Confidence interval; EVAC: Endovascular variable aortic control; $\mathrm{FiO}_{2}$ : Fractional concentration of oxygen in inspired air; I/R: Ischemia-reperfusion; OR: Odds ratio; $\mathrm{PaO}_{2}$ : Partial pressure of oxygen in arterial blood; PEEP: Positive end-expiratory pressure; PPCs: Postoperative pulmonary complications; PRBCs: Packed red blood cells; REBOA: Resuscitative endovascular balloon occlusion of the aorta; ROC: Receiver operating characteristic; ROS: Reactive oxygen species; $\mathrm{SpO}_{2}$ : Peripheral blood oxygen saturation; VIF: Variance inflation factor
\end{abstract}

\section{Acknowledgements}

The authors would like to thank Professor Wei Guo (director of the Department of Bone Oncology, Peking University People's Hospital) for his advice and help in writing the manuscript.

\section{Authors' contributions}

$J J X$ contributed to the conception and design of this manuscript, the acquisition of the data and drafting of the manuscript. HYZ was responsible for the analysis and interpretation of the data. XDZ contributed to the data collection. YF conceived of the study and participated in its design and coordination, revised the manuscript and gave final approval of the version to be published. All authors have read and approved the final version of this manuscript in its entirety.

\section{Author's information}

Junjun Xu and Huiying Zhao are considered as co-first authors.

Yi Feng is the corresponding author.

\section{Funding}

This study was supported by the National Key Research and Development Program of China (Grant No. 2018YFC2001905) and research fund provided by Peking University People's Hospital Research and Development Funds No. RDY2019-43.

\section{Availability of data and materials}

The datasets used and analyzed during the current study are available from the corresponding author on request.

\section{Ethics approval and consent to participate}

This was a retrospective cohort study approved by the Institutional Review Board (IRB) of Peking University People's Hospital (IRB no.2019PHB038-01; approved on February 28, 2019). For this type of study, formal consent is not required.

Consent for publication

Not applicable.

\section{Competing interests}

There is no conflict of interest of any authors in relation to the submission.

\section{Author details}

'Department of Anesthesiology, Peking University People's Hospital, No. 11 Xizhimen South Street, Xicheng District, Beijing 10044, China. ${ }^{2}$ Department of Critical Care Medicine, Peking University People's Hospital, No. 11 Xizhimen South Street, Beijing, China.

Received: 21 January 2020 Accepted: 11 May 2020

Published online: 16 May 2020

\section{References}

1. Ledgerwood AM, Kazmers M, Lucas CE. The role of thoracic aortic occlusion for massive hemoperitoneum. J Trauma. 1976;16:610-5. https://doi.org/10. 1097/00005373-197608000-00004

2. Costantini TW, Coimbra R, Holcomb JB, Podbielski JM, Catalano R, Blackburn A, et al. Current management of hemorrhage from severe pelvic fractures: results of an American Association for the Surgery of Trauma multiinstitutional trial. J Trauma Acute Care Surg. 2016;80:717-23. https://doi.org/ 10.1097/TA.0000000000001034.

3. Tang X, Guo W, Yang R, Tang S, Dong S. Use of aortic balloon occlusion to decrease blood loss during sacral tumor resection. J Bone Joint Surg Am. 2010;92:1747-53. https://doi.org/10.2106/JBJS.I.01333.

4. Luo Y, Duan H, Liu W, Min L, Shi R, Zhang W, et al. Clinical evaluation for lower abdominal aorta balloon occluding in the pelvic and sacral tumor resection. J Surg Oncol. 2013;108:148-51. https://doi.org/10.1002/jso.23376.

5. Zhang Y, Guo W, Tang X, Yang R, Yan T, Dong S, et al. Can aortic balloon occlusion reduce blood loss during resection of sacral tumors that extend into the lower lumber spine? Clin Orthop Relat Res. 2018;476:490-8. https:// doi.org/10.1007/s11999.0000000000000053.

6. Ordoñez CA, Manzano-Nunez R, Parra MW, Rasmussen TE, Nieto AJ, HerreraEscobar JP, et al. Prophylactic use of resuscitative endovascular balloon occlusion of the aorta in women with abnormal placentation: a systematic review, meta-analysis, and case series. J Trauma Acute Care Surg. 2018;84: 809-18. https://doi.org/10.1097/TA.0000000000001821.

7. Brede JR, Lafrenz T, Klepstad P, Skjærseth EA, Nordseth T, Søvik E, et al. Feasibility of pre-hospital resuscitative endovascular balloon occlusion of the aorta in non-traumatic out-of-hospital cardiac arrest. J Am Heart Assoc. 2019;8:e014394. https://doi.org/10.1161/JAHA.119.014394.

8. Kalogeris T, Baines CP, Krenz M, Korthuis RJ. Ischemia/reperfusion. Compr Physiol. 2017;7:113-70. https://doi.org/10.1002/cphy.c160006.

9. Chao CS, Tsai CS, Wang YH, Liu YH, Chen JM, Chang YP, et al. Porcine model for observing changes due to ischemia/reperfusion injury secondary to intra-abdominal endovascular balloon occlusion. Exp Biol Med. 2016;241: 1834-43. https://doi.org/10.1177/1535370216648802.

10. Perlikos F, Lagiou M, Papalois A, Rizou T, Kroupis C, Toumpoulis IK. Lazaroid (U-74389G) ameliorates lung injury due to lipid peroxidation and nitric oxide synthase-dependent reactive oxygen species generation caused by remote systematic ischemia-reperfusion following thoracoabdominal aortic occlusion. Int J Surg. 2018;55:156-61. https://doi.org/10.1016/.jijsu.2018.05. 735

11. Adembri C, Kastamoniti E, Bertolozzi I, Vanni S, Dorigo W, Coppo M, et al. Pulmonary injury follows systemic inflammatory reaction in infrarenal aortic surgery. Crit Care Med. 2004;32:1170-7. https://doi.org/10.1097/01.ccm. 0000124875.98492 .11$.

12. Kirmeier E, Eriksson LI, Lewald H, Jonsson Fagerlund M, Hoeft A, Hollmann $\mathrm{M}$, et al. Post-anaesthesia pulmonary complications after use of muscle relaxants (POPULAR): a multicentre, prospective observational study. Lancet Respir Med. 2019;7:129-40. https://doi.org/10.1016/S2213-2600(18)30294-7.

13. Canet J, Gallart L, Gomar C. Paluzie G, Vallès J, Castillo J, et al. Prediction of postoperative pulmonary complications in a population-based surgical cohort. Anesthesiology. 2010:113:1338-50. https://doi.org/10.1097/ALN. ob013e3181fc6e0a. 
14. Mazo V, Sabaté S, Canet J, Gallart L, de Abreu MG, Belda J, et al. Prospective external validation of a predictive score for postoperative pulmonary complications. Anesthesiology. 2014;121:219-31. https://doi.org/10.1097/ ALN.0000000000000334.

15. Neto AS, da Costa LGV, Hemmes SNT, Canet J, Hedenstierna G, Jaber S, et al. The LAS VEGAS risk score for prediction of postoperative pulmonary complications: an observational study. Eur J Anaesthesiol. 2018:35:1-11. https://doi.org/10.1097/EJA.0000000000000845.

16. Li S, Zhou K, Lai Y, Shen C, Wu Y, Che G. Estimated intraoperative blood loss correlates with postoperative cardiopulmonary complications and length of stay in patients undergoing video-assisted thoracoscopic lung cancer lobectomy: a retrospective cohort study. BMC Surg. 2018;18:29-40. https:// doi.org/10.1186/s12893-018-0360-0.

17. Stannard A, Eliason JL, Rasmussen TE. Resuscitative endovascular balloonocclusion of the aorta (REBOA) as an adjunct for hemorrhagic shock J Trauma. 2011;71:1869-72. https://doi.org/10.1097/TA.0b013e31823fe90c.

18. Saito N, Matsumoto H, Yagi T, Hara Y, Hayashida K, Motomura T, et al. Evaluation of the safety and feasibility of resuscitative endovascular balloon occlusion of the aorta. J Trauma Acute Care Surg. 2015;78:897-903. https:// doi.org/10.1097/TA.0000000000000614.

19. Wang J, Qiao L, Li S, Yang G. Protective effect of ginsenoside Rb1 against lung injury induced by intestinal ischemia-reperfusion in rats. Molecules. 2013;18:1214-26. https://doi.org/10.3390/molecules18011214.

20. Yang L, Chong-Qi T, Hai-Bo S, Lan Z, Tian-Fu Y, Hong D, et al. Appling the abdominal aortic-balloon occluding combine with blood pressure sensor of dorsal artery of foot to control bleeding during the pelvic and sacrum tumors surgery. J Surg Oncol. 2008;97:626-8. https://doi.org/10.1002/jso. 21026.

21. Zhang L, Gong Q, Xiao H, Tu C, Liu J. Control of blood loss during sacral surgery by aortic balloon occlusion. AnesthAnalg. 2007;105:700-3. https:// doi.org/10.1213/01.ane.0000278135.85206.4e.

22. $\mathrm{Mi} \mathrm{C}$, Lu H, Liu H. Surgical excision of sacral tumors assisted by occluding the abdominal aorta with a balloon dilation catheter: a report of 3 cases. Spine. 2005;30:E614-6. https://doi.org/10.1097/01.brs.0000182111.64825.0f.

23. Kuckelman JP, Barron M, Moe D, Derickson M, Phillips C, Kononchik J, et al. Extending the golden hour for zone 1 resuscitative endovascular balloon occlusion of the aorta: improved survival and reperfusion injury with intermittent versus continuous resuscitative endovascular balloon occlusion of the aorta in a porcine severe truncal hemorrhage model. J Trauma Acute Care Surg. 2018;85:318-26. https://doi.org/10.1097/TA.0000000000001964.

24. Johnson MA, Neff LP, Williams TK, DuBose JJ, EVAC Study Group. Partial resuscitative balloon occlusion of the aorta (P-REBOA): clinical technique and rationale. J Trauma Acute Care Surg. 2016;81:S133-7. https://doi.org/10. 1097/TA.0000000000001146.

25. Williams TK, Neff LP, Johnson MA, Ferencz SA, Davidson AJ, Russo RM, et al. Extending resuscitative endovascular balloon occlusion of the aorta: endovascular variable aortic control in a lethal model of hemorrhagic shock. J Trauma Acute Care Surg. 2016;81:294-301. https://doi.org/10.1097/TA. 0000000000001075.

26. Williams TK, Tibbits EM, Hoareau GL, Simon MA, Davidson AJ, DeSoucy ES, et al. Endovascular variable aortic control (EVAC) versus resuscitative endovascular balloon occlusion of the aorta (REBOA) in a swine model of hemorrhage and ischemia reperfusion injury. J Trauma Acute Care Surg. 2018:85:519-26. https://doi.org/10.1097/TA.0000000000002008.

27. Tassiopoulos AK, Carlin RE, Gao Y, Pedoto A, Finck CM, Landas SK, et al. Role of nitric oxide and tumor necrosis factor on lung injury caused by ischemia/ reperfusion of the lower extremities. J Vasc Surg. 1997;26:647-56. https:// doi.org/10.1016/s0741-5214(97)70065-X.

28. Takhtfooladi H, Takhtfooladi M, Moayer F, Mobarakeh S. Melatonin attenuates lung injury in a hind limb ischemia-reperfusion rat model. Rev Port Pneumol (2006). 2015;21:30-5. https://doi.org/10.1016/j.rppnen.2014.01.010.

29. Kassab AA, Aboregela AM, Shalaby AM. Edaravone attenuates lung injury in a hind limb ischemia-reperfusion rat model: a histological, immunohistochemical and biochemical study. Ann Anat. 2019;228:151433. https://doi.org/10.1016/j.aanat.2019.151433.

30. Dorsa RC, Pontes JC, Antoniolli AC, Silva GV, Benfatti RA, Santos CH, et al. Effect of remote ischemic postconditioning in inflammatory changes of the lung parenchyma of rats submitted to ischemia and reperfusion. Rev Bras Cir Cardiovasc. 2015;30:353-9. https://doi.org/10.5935/1678-9741.20150005.

31. Roy S, Sadowitz B, Andrews P, Gatto LA, Marx W, Ge L, et al. Early stabilizing alveolar ventilation prevents acute respiratory distress syndrome: a novel timing-based ventilatory intervention to avert lung injury. J Trauma Acute Care Surg. 2012;73:391-400. https://doi.org/10.1097/TA.0b013e31825c7a82.

\section{Publisher's Note}

Springer Nature remains neutral with regard to jurisdictional claims in published maps and institutional affiliations.
Ready to submit your research? Choose BMC and benefit from:

- fast, convenient online submission

- thorough peer review by experienced researchers in your field

- rapid publication on acceptance

- support for research data, including large and complex data types

- gold Open Access which fosters wider collaboration and increased citations

- maximum visibility for your research: over $100 \mathrm{M}$ website views per year

At BMC, research is always in progress.

Learn more biomedcentral.com/submissions 